\title{
Pengaruh Kegiatan Herbarium Terhadap Perkembangan Kreativitas Anak di PAUD Kasih Ibu I Luar Parit
}

\author{
Endang Susri Ranti \\ Nur Hazizah \\ Program Studi Pendidikan Guru Pendidikan Anak Usia Dini Fakultas Ilmu Pendidikan \\ Universitas Negeri Padang \\ Email: endangsusriranti057@gmail.com
}

Received March 2019, Accepted April 2019, Published April 2019

\begin{abstract}
The purpose of this study was to determine the creativity development of children 5-6 years old with herbarium activities in PAUD Kasih Ibu I Luar Parit. The creativity development activities in the field use dry leaf collage activities and serveral other activities such as drawing coloring, and forming fruits from plasticine. But the work produced is almost exactly the same as the teacher's example. Through this herbarium activity researhers want to see the creativity development of children 5-6 years. Quantitative reasearch with experimental methods in the form of quasi experimental is a method in this study. All children in PAUD Kasih Ibu I Luar Parit totaling 34. Group B1 experimental sample and B2 control sample with 12 children each class. Purposive sampling. As for the technique of collecting data using deed test and oral test.statement instrumen grid is used as a data collection tool. The results of the average experimental 77,77 and the control 70,83. So the use of herbarium activities had a significant effect on the development of creativity of children 5-6 years old at the PAUD Kasih Ibu I Luar Parit academic years 2018/2019.
\end{abstract}

Keywords: Herbarium Activity, Creativity of Children 5-6 Years, Quasi Experimental

Abstrak: Tujuan penelitian ini untuk mengetahui perkembangan kreativitas anak 5-6 tahun dengan kegiatan herbarium di PAUD kasih Ibu I Luar Parit. Kegiatan perkembangan kreativitas yang ada dilapanagn menggunakan kegiatan kolase daun kering dan beberapa kegiatan lainnya seperti menggambar, mewarnai, dan membentuk buah-buahan dari plastisin. Namun karya yang dihasilkan hampir sama persis dengan yang dicontohkan guru. Melalui kegiatan herbarium ini peneliti ingin melihat perkembangan kreativitas anak 5-6 tahun. Penelitian kuantitatif dengan metode eksperimen dalam bentuk quasi eksperimental merupakan metode dalam penelitian ini. Seluruh ank di PAUD Kasih Ibu I Luar Parit berjumlah 34 anak merupakn populasi dalam penelitian. Kelompok BI sampel eksperimen dan B2 sampel kontrol dengan jumlah 12 anak tiap-tiap kelas. Purposive sampling merupakan teknik yang digunakan dalam pengambilan sampel. Adapun teknik pengumpulan data menggunakan tes perbuatan dan tes lisan. Kisi-kisi Instrumen pernyataan di gunakan sebagai alat pengumpul data. Hasil uji perbedaan menunjukkan hasil rat-rata eksperimen 77,77 dan kontrol 70,83. Jadi penggunaan kegiatan herbarium berpngaruh signifikan terhadap perkembangan kreativitas anak 5-6 tahun di PAUD Kasih Ibu I Luar Parit ajaran 2018/2019.

Kata Kunci: Kegiatan Herbarium, Kreativitas Anak 5-6 Tahun, Quasi Eksperimen

\section{PENDAHULUAN}

PAUD yaitu pendidikan yang ditujukan untuk anak berusia dari 0-6 tahun yang dilakukan dengan memberi rangsangan pendidikan dalam membantu pertumbuhan dan perkembangan jasmani serta rohani agar anak memiliki bekal dalam memasuki pendidikan yang lebih lanjut, Mulyasa (2014: 48). PAUD adalah Pendidikan yang sangat penting bagi anak di kemudian hari, Delfi (2013: 93).

Yaswinda, Yulsyofriend, dan Mayar (2018:13) Pendidikan anak usia dini merupakan pendidikan yang diberikan dari anak lahir sampai berumur delapan tahun.
Pendidikan bagi anak usia dini merupakan dasar bagi pembentukan kepribadian manusia secara utuh, yaitu ditandai dengan karakter, budi pekerti luhur, pandai dan terampil.

PAUD di selenggarakan dalam bentuk tiga jalur, yaitu jalur formal seperti taman kanak-kanak, jalur non formal seperti $\mathrm{KB}$, TPA dan satuan PAUD sejenisnya dan jalur informal seperti keluarga.

TK adalah satuan pendidikan anak usia dini pada jalur pendidikan formal yang menyelenggarakan program pendidikan bagi anak usia 4-6 tahun. Usia 4-6 tahun merupakan masa peka bagi anak, dimana anak mulai 
sensitif untuk menerima berbagai upaya pengembangan seluruh potensi anak.

Jadi anak memerlukan program pendidikan yang mampu membuka kapasitas tersembunyi tersebut melalui pembelajaran bermakna sedini mungkin. Pengembangan kreativitas anak merupakan salah satu tujuan yang harus dikembangkan di PAUD. Kreativitas menurut Suryana (2016: 207) adalah kemampuan anak untuk menciptakan suatu kombinasi baru atau sesuatu yang baru, berdasarkan unsur-unsur yang sebelumnya telah ada menjadi sesuatu yang bermanfaat dan bermakna. selanjutnya Ismaniar \& Hazizah (2018:14) kreativitas adalah suatu kemampuan yang dimiliki oleh seseorang dalam menghasilkan/menciptakan sesuatu yang baru dalam memecahkan masalah yang sedang dihadapi, lebih jauh sesuatu yang baru itu dapat berupa benda, ide, gagasan, model, strategi dan sebagainya yang bermanfaat/bernilai bagi dirinya dan orang lain.

Suyadi (2014:171) seni merupakan suatu stimulasi kreatif. Kreativitas seni di taman kanak-kanak memiliki peranan yang penting sebagai upaya pengenalan untuk berekspresi, berimajinasi, berkreasi, rasa estetis, dan artistik dalam suasana bermain kreatif. Kegiatan yang dapat mengembangkan kreativitas anak yaitu melalui kegiatan herbarium.

Mertha dkk (2018: 82) herbarium kering merupakan tumbuhan yang telah diawetkan dengan cara dikeringkan. Herbarium akan menjadi kegiatan yang sangat menyenangkan bagi anak-anak karena menggunakan bagian tanaman untuk diawetkan merupakan suatu hal yang unik sehingga anak tertarik dan antusias untuk melakukannya. Proses herbarium ini membutuhkan daun-daunan sehingga sangat mudah untuk dilakukan dan sangat menyenangkan bagi anak.

Hasil pengamatan peneliti di PAUD Kasih Ibu 1 Luar Parit, peneliti menemukan masalah tentang kreativitas anak kurang berkembang optimal. Hal ini terlihat pada kegiatan perkembangan kreativitas: mewarnai khaligrafi, dimana rata-rata hasil mewarnai anak hampir sama dengan yang dicontohkan guru. Begitupun dalam pengembangan kreativitas lainnya, membuat buah-buahan dengan yang dicontohkan guru. Hal ini disebabkan karena kurangnya kreativitas anak dalam mencipta karya baru. Untuk mengatasi masalah tersebut peneliti mencari alternatif penyelesaian yaitu melalui kegiatan herbarium.

Oleh karena itu herbarium ini diharapkan dapat mengembangkan kreativitas anak. Upaya pemecahan masalah tersebut peneliti mewujudkan dalam bentuk penelitian eksperimen "Pengaruh Kegiatan Herbarium Terhadap Perkembangan Kreativitas Anak di PAUD Kasih Ibu 1 Luar Parit"

\section{METODE PENELITIAN}

Penelitian eksperimen dalam bentuk quashi experimental merupakan metode dalam penelitian ini. Sugiyono (2017:107) metode eksperimen adalah metode penelitian untuk mencari pengaruh perlakuan tertentu dalam kondisi yang terkendalikan. Selanjutnya Sugiyono (2017:114) mengatakan desain quasi eksperimen mempunyai kelompok kontrol, tetapi tidak dapat berfungsi sepenuhnya mengontrol variabel-variabel luar yang mempengaruhi pelaksanaan eksperimen.

Populasi dalam penelitian ini adalah PAUD Kasih Ibu 1 Luar Parit. Sampling Purposive adalah teknik pengambilan sampel dalam penelitian ini. Sugiyono (2017:124) sampling purposive adalah teknik penentuan, sampel dengan pertimbangan tertentu. Kelompok yang akan dijadikan adalah kelompok B1 dan B2. Tingkat kemampuan anak yang sama, jumlah anak yang sama yang akan dijadikan pertimbangan.

Teknik pengumpulan data menggunakan tes buatan guru yang disusun dalam bentuk tes lisan dan tes perbuatan. Menurut Latisma (2011:20) tes lisan adalah tes dilakukan dengan mengadakan tanya jawab 
secara langsung bersama peserta didik. Sedangkan tes perbuatan adalah tes yang pelaksanaan tugasnya dinyatakan dengan perbuatan atau unjuk kerja.

Dalam penelitian ini peneliti membuat tes berupa instrumen pernyataan yang akan dicapai oleh anak. Di setiap butir instrumen pernyataan telah diberi skor. Titik tolak dalam penyusunan instrumen adalah variabelvariabel penelitian yang ditetapkan untuk diteliti, selanjutnya diberikan aspek yang akan diukur. Dari indikator kemudian dijabarkan menjadi butir-butir (item) pertanyaan atau pernyataan.

Arikunto (2014:211) validitas adalah suatu ukuran yang menunujukkan tingkattingkat kevalidan atau kesahihan suatu instrumen. Selanjutnya menurut Basuki (2014:22) valid artinya "sah atau atau cocok, atau benar". Menurut Arikunto (2014:221) reliabilitas adalah suatu instrumen cukup dapat dipercaya sebagai alat pengumpul data karena instrumen tersebut sudah baik. Basuki dan Hariyanto (2014:22) suatu tes dikatakan reliabel jika dapat dipercaya, dikatakan bisa di percaya apabila hasil yang di capai oleh tes itu konstan atau tetap. Pengujian reliabilitas instrumen dapat dilakukan dengan rumus alpha. Analisis data dalam penelitian ini adalah membandingkan perbedaan dari dua rata-rata ini, yang terlebih dahulu dilakukan uji normalitas dan uji homogenitas sebelum dilakukan uji-t (t-test).

\section{HASIL DAN PEMBAHASAN Hasil Penelitian}

Hasil temuan penelitian ini di uraikan melalui grafik dan tabel yang sebelumnya data diolah dengan statistik dan temuan lapangan

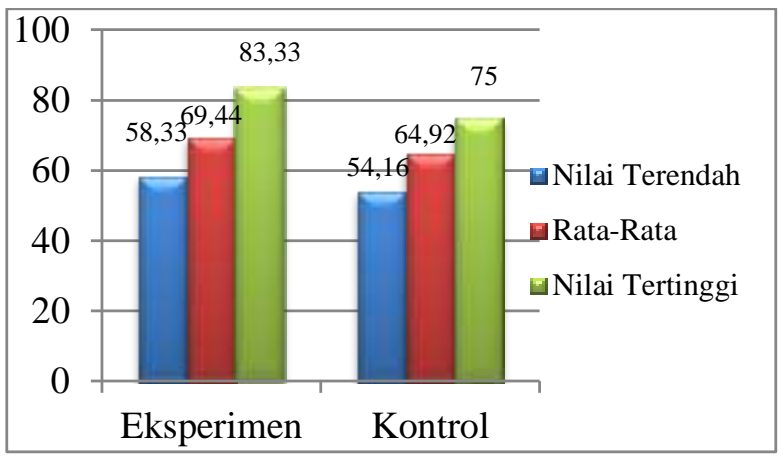

Gambar 1. Data Perbandingan Hasil Pre-Test Perkembangan kreativitas Anak 5-6 Tahun Di Kelas Eksperimen Dan Kelas Kontrol

Hasil dari penelitian dilakukan uji hipotesis dengan menggunakan uji t. Dimana sebelum uji t terlebih dahulu melakukan uji normalitas dan uji homogenitas. Berdasarkan pengujian hipotesis tentang hasil pre-test kelas kontrol dan kelas eksperimen di peroleh angka rata-rata kelas kontrol yaitu $\mathbf{6 4 , 9 2}$ dan angka rata-rata kelas eksperimen $\mathbf{6 9 , 4 4}$. Hasil analisis data yang dilakukan terdapat $t_{\text {hitung }}$ sebesar 1,49668 dibandingkan dengan $\alpha$ $0,05 \quad\left(t_{\text {tabel }}=\mathbf{2 , 0 7 3 8 7}\right) \quad$ dengan derajat kebebasan 22 dengan demikian $t_{\text {hitung }}<t_{\text {tabel }}$ yaitu 1, $49668<2,07387$. Jadi hipotesis $\mathrm{Ha}$ ditolak atau $\mathrm{H}_{0}$ diterima. Kesmpulannya yaitu tidak terdapat perbedaan yang signifikan antara perkembangan kreativitas anak kelas kontrol dan kelas eksperimen.

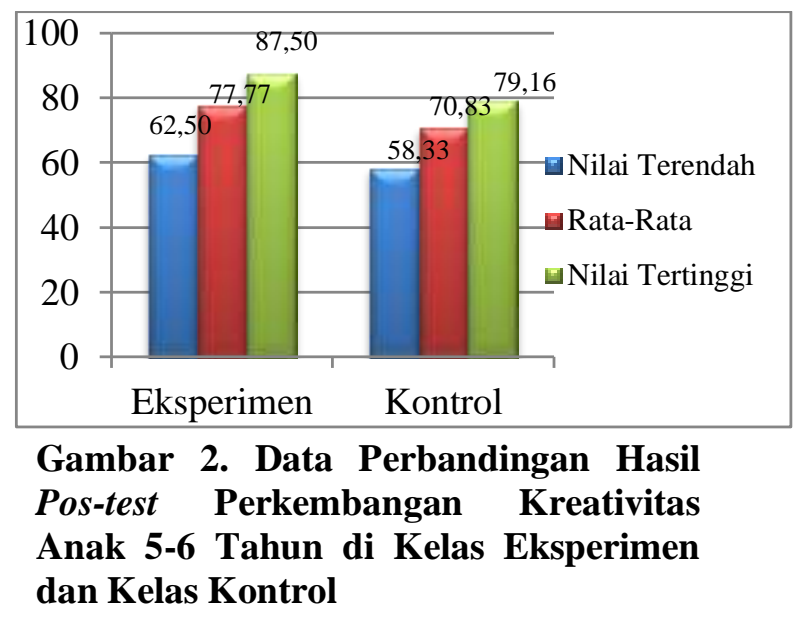


Data hasil penelitian tentang post-test yang dilakukan diperoleh angka rata-rata kelas kontrol 70,83 dan rata-rata kelas eksperimen 77,77. Maka di perole $t_{\text {hitung }}$ sebesar 2,161993 dengan $\alpha 0,05 \quad\left(\mathrm{t}_{\text {tabel }}=\right.$ 2,07387) dengan $\mathrm{dk}=22$. Dengan demikian $\mathrm{t}_{\text {hitung }}>\mathrm{t}_{\text {tabel }}$ yaitu 2,15413>2,07387 jadi hipotesis $\mathrm{H}_{\mathrm{a}}$ di terima atau $\mathrm{H}_{0}$ ditolak. maka kegiatan herbarium dapat berpengaruh terhadap perkembangan kreativitas anak 5-6 tahun di PAUD Kasih Ibu I Luar Parit.

Hasil perbandingan hitungan nilai pre-test dan nilai post-test dalam bentuk tabel dapat dilihat melalui tabel 1. Hasil perbandingan hitung pre-test dan post-test dalam bentuk grafik dapat dilihat melalui grafik 3 .

Tabel 1. Perbandingan Hasil Perhitungan Nilai Pre-test dan Nilai Post-test

\begin{tabular}{lcccc}
\hline \multicolumn{1}{c}{ variabel } & \multicolumn{2}{c}{ Pre-test } & \multicolumn{2}{c}{ Post-test } \\
\cline { 2 - 5 } & $\begin{array}{c}\text { Eksperi } \\
\text { men }\end{array}$ & $\begin{array}{c}\text { Kont } \\
\text { rol }\end{array}$ & $\begin{array}{c}\text { Eksp } \\
\text { erime } \\
\text { n }\end{array}$ & $\begin{array}{c}\text { Kontro } \\
\mathbf{l}\end{array}$ \\
\hline $\begin{array}{l}\text { Nilai } \\
\text { tertinggi }\end{array}$ & 78,12 & 71,87 & 87,50 & 81,25 \\
\hline $\begin{array}{l}\text { Nilai } \\
\text { Terendah }\end{array}$ & 59,37 & 56,25 & 68,75 & 62,50 \\
\hline Rata-rata & 69,00 & 65,36 & 78,64 & 72,91 \\
\hline
\end{tabular}

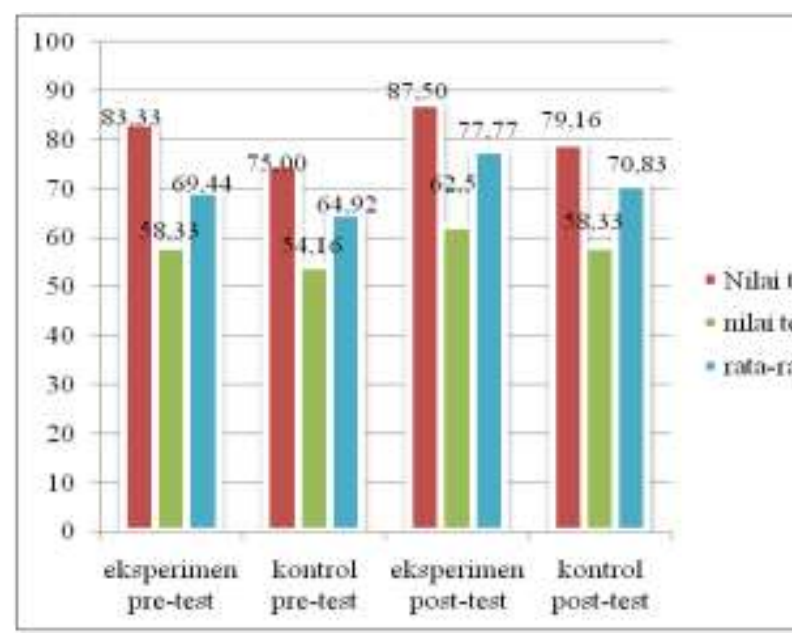

Grafik 3. Data Perbandingan Pre-test dan Post-test Perkembangan Kreativitas Anak 5-6 Tahun Kelas Eksperimen dan Kelas Kontrol
Grafik diatas menyatakan bahwa kegiatan herbarium kering lebih berpengaruh dibandingkan kegiatan kolase daun kering dalam pengembangan kreativitas anak 5-6 tahun. Hal ini terlihat bahwa nilai yang didapat anak kelas kontrol dengan rata-rata 70,83 lebih rendah dibandingkan nilai yang didapat anak kelas eksperimen dengan ratarata 77,77 .

\section{Pembahasan Hasil Penelitian}

Sebelum melakukan penelitian peneliti membuat kisi-kisi instrumen yang akan menilai perkembangan kreativitas anak. Dimana kisi-kisi ini telah divalidatori oleh dosen ahli di bidang kreativitas. Setelah dapat persetujuan oleh validator peneliti menguji kevalidan dari sebuah kisi-kisi tersebut di TK Aisyiyah VI Ulak Karang Padang. Setelah data didapatkan selanjutnya peneliti melakukan uji validasi tes dan uji reliabilitas tes untuk mengetahui apakah kisi-kisi tersebut akurat, nyata/benar. Setelah di uji valid dan reliabel suatu kisi-kisi tersebut maka dari 11 item pernyataan terdapat 6 item pernyataan yang valid. 6 item tersebutlah yang peneliti gunakan dalam menilai perkembangan kreativitas anak 5-6 tahun di PAUD Kasih Ibu 1 Luar Parit.

Saat peneliti terjun kelapangan untuk melakukan penelitian terlebih dahulu peneliti mengadakan pre-test untuk melihat kemampuan awal anak, yaitu peneliti menggunakan kegiatan herbarium kering di kelas eksperimen dan kegiatan kolase daun kering dikelas kontrol. Saat peneliti melakukan pre-test diawal penelitian peneliti melihat bahwa masih banyak anak yang dibantu guru dalam menyelesaikan tugasnya. Dikarenakan kegiatan herbarium kering merupakan kegiatan yang baru bagi anak dan belum pernah dipelajari anak sebelumnya.

Setelah diadakan pre-test kelas eksperimen diberikan perlakuan sebanyak 3 kali dan selanjutnya diadakan post-test untuk melihat hasil akhir anak setelah diberikan perlakuan, pada saat post-test dilakukan terlihat banyak anak yang sudah mampu 
menyelesaikan tugasnya dengan baik dan membantu temannya dalam menyelesaikan tugasnya.

Pada saat penelitian terlihat anak sangat semangat dan antusias dalam kegiatan herbarium kering karena merupakan kegiatan yang baru di PAUD tersebut dan dalam proses penyusunan hasilnya anak juga di beri kebebasan dalam menyusunnya tanpa harus mengikuti pola yang sudah ada dengan durasi kurang lebih 30 menit.

Sedangkan pada kelas kontrol B2 menggunakan kegiatan kolase daun kering untuk pengembangan kreativitas anak. Terlihat anak kurang memberikan respon ketertarikan dalam melakukan kegiatan kolase, karena kolase merupakan kegiatan yang bersifat mengisi pola yang sudah ada dan anak juga tidak diberi kebebasan dalam mengembangkan ide mereka, sehingga membuat anak menjadi kaku dan kreativitasnya tidak berkembang. Jadi dapat disimpulkan bahwa kegiatan herbarium lebih baik dari pada kegiatan kolase daun kering. Terlihat bahwa nilai rata-rata eksperimen lebih tinggi di bandingkan kontrol.

Penelitian ini beranjak dari teori dan juga pendapat ahli yang mengataan bahwa tujuan kegiatan herbarium menurut Rachmawati dan Kurniati (2011:129) adalah (1) Meningkatkan kemampuan berfikir kreatif dan kritis, mengembangkan kemampuan pengamatan, ketelitian, belajar mandiri, serta mengembangkan rasa igin tahu anak; (2) Mengenal nama bagian-bagian utama tumbuhan.

Dimana kreativitas menurut Suryana (2016:207) kreativitas merupakan kemampuan untuk menciptakan suatu yang baru atau kombinasi baru berdasarkan unsur-unsur yang sebelumnya telah ada menjadi sesuatu yang bermanfaat. selanjutnya Ismaniar \& Hazizah (2018:14) kreativitas adalah suatu kemampuan yang dimiliki oleh seseorang dalam menghasilkan/menciptakan sesuatu yang baru dalam memecahkan masalah yang sedang dihadapi, lebih jauh sesuatu yang baru itu dapat berupa benda, ide, gagasan, model, strategi dan sebagainya yang bermanfaat/bernilai bagi dirinya dan orang lain.

\section{SIMPULAN}

Hasil penelitian menunujukkan bahwa kegiatan herbarium mempengaruhi perkembangan kreativitas anak 5-6 tahun dalam mencipta karya baru di PAUD Kasih Ibu 1 Luar Parit. Sebelum diberikan perlakuan (treatment) kegiatan herbarium dalam pengembangan kreativitas anak usia dini termasuk dalam kategori rendah dan sedang. Dari 6 instrumen pernyataan yang diukur semua berada pada indikator MB dan BSH sedangkan sesudah diberi perlakuan dan diadakan post-test terlihat bahwa kegiatan herbarium berada dalam kategori BSH dan BSB. Maka terdapat perubahan perkembangan kreativitas anak 5-6 tahun dari sebelum dan sesudah diberikan perlakuan dalam penelitian.

Implikasinya, jika ingin meningkatkan perkembangan kreativitas anak dalam mencipta karya baru pada anak 5-6 tahun lebih optimal selain memanfaatkan sumber belajar dan APE perlu dilakukan modifikasi media melalui penelitian eksperimen yang lebih banyak lagi pada kegiatan, media maupun permainan yang dapat meningkatkan perkembangan kreativitas anak usia 5-6 tahun dalam mencipta karya baru.

\section{Saran}

Kepada guru PAUD Kasih Ibu 1 Luar Parit agar kegiatan herbarium dapat dijadikan media pembelajaran untuk menstimulasi perkembangan kreativitas anak dalam mencipta karya baru. Melalui kegiatan herbarium diharapkan kreativitas dapat berkembang dengan baik. Kegiatan herbarium dapat dijadikan inspirasi dalam melakukan penelitian pada aspek yang berbeda bagi peneliti selanjutnya. 
Volume 6, Nomor 1, April 2019, hal 43 - 48

\section{DAFTAR PUSTAKA}

Arikunto, S. (2014). Prosedur Penelitian Suatu Pendekatan Praktik. Rineka Cipta: Jakarta.

Basuki, I. \& Yanto, H. 2014, Asesmen Pembelajaran, Bandung, PT Remaja Rosda Karya.

Eliza, D. (2013). Penerapan Model Pembelajaran Kontekstual Learning (CTL) Berbasis Centra di Taman-Kanak-Kanak

Ismaniar \& Nur, H. (2018). Buku Ajar Pelatihan Kreativitas Deucoupage bagi Pendidikan PAUD. Jurusan Pendidikan Luar Sekolah Fakultas Ilmu Pendidikan Universitas Negeri Padang: Padang.

Latismah, D. J. (2011). Evaluasi PendidikanUNP Press, Padang

Mertha, I. G., dkk. (2018). Pelatihan Teknik Pembuatan Herbarium Kering dan identifikasi tumbuhan berbasis lingkungan sekolah di SMAN 4 Mataram. Jurnal Pendidikan dan Pengabdian masyarakat. Vol. 1 No. 1, Februari 2018 E-ISSN. 2614-7939 P-ISSN. 26147947.

Mulyasa. (2014). Manajemen PAUD. Remaja Rosda Karya: Bandung

Murni, P., dkk. (2015). Lokakarya Pembuatan Herbarium Untuk Pengembangan Media Pembelajaran Biologi Di Man Cendikia Muaro Jambi. Jurnal Pengabdian Pada Masyarakat Volume 30, Nomor 2 April - Juni 2015.

Rachmawati, Y. \& Kurniati, E. (2011). Strategi Pengembangan Kreativitas Pada Anak Usia Taman Kanak-Kanak. Jakarta: Kencana

Sriandila, R. (2016). Pengaruh Oshibana Terhadap Perkembangan
Kreativitas Seni di Taman

Kanak-Kanak Kemala

Bhayangkari 12 Pariaman.

Belum dipublikasikan.

Sugiyono. (2017). Metode Penelitian Kuantitatif, Kualitatif dan $R \& D$. Alfabeta: Bandung

Suryana, D. (2016). Pendidikan Anak Usia Dini Stimulasi \& Aspek Perkembangan Anak. Kencana: Padang

Suyadi. (2014). Teori Pembelajaran Anak Usia Dini Dalam Kajian Neurosains. Bandung: Remaja Rosdakarya

Yaswinda, Y., \& Mayar, F. (2018). Pengembangan Bahan Pembelajaran Sains Berbasis Multisensori Ekologi Bagi Guru Paud Kecamatan Tilatang Kamang Kabupaten Agam. Yaa Bunayya : Jurnal Pendidikan Anak Usia Dini Volume2 No.II November 2018 